\title{
I CONGRESSO BRASILEIRO de EDUCAÇÃo ESPECIAL: PPGEEs E ABPEE EM PARCERIA NA RETOMADA DE UM IDEAL
}

\author{
Adriana Augusto Raimundo de AGUIAR ${ }^{1}$
}

MENDES, E. G.; ALMEIDA, M. A.; WILLIAMS, L. C. A. (Org.) Temas em educação especial: avanços recentes. São Carlos: EdUFSCar, 2004.

Nossa sociedade parece solicitar habilidades cada vez mais complexas de seus cidadãos para que estes atendam as exigências do mundo moderno. Diante dessecontexto atual edas políticas educacionais vigentes deinclusão da população com necessidades educativas especiais nas escolas regulares, écrescentea discussão de que as escolas devem promover habilidades que permitam aos al unos atuarem como adultos e membros comunitários eficientes.

Essas demandas dão à Educação Especial lugar de destaque no âmbito da pesquisa científica em Educação. Programas de pós-graduação em educação têm contribuído amplamente para o aumento da produção científica em Educação Especial no Brasil. Dentreesses programas destaca-seo Programa dePós-graduação em Educação Especial da UFSCar (PPGEEs), quealém decontribuir para a formação de mestres e doutores em Educação Especial, se preocupou ainda em abrir um espaço científico, promovendo e organizando eventos, para divulgar o conhecimento produzido, promover intercâmbio entre pesquisadores e profissionais, e atender a demanda emergente por novas práticas decorrentes das diretrizes educacionais de inclusão escolar recentemente adotada pelo país.

O presentelivro éo registro eo compartilhamento deum marco na retomada desse espaço de intercâmbio científico, na área da Educação Especial, conquistado pelo PPGEEs e pela ABPEE de 1982 a 1995, concretizado com a organização do I Congresso Brasileiro de Educação Especial em 2003. N ele, é possível identificar a contribuição do PPGEEs para a produção de conhecimento sobre os processos de desenvolvimento edeadaptação de clientelas com diferentes tipos denecessidades especiais, tais como: diferentes deficiências e população de risco por maus tratos e abuso e a contemplação tanto das características do PPGEEs (interdisciplinaridade, articulação entre pesquisa básica e aplicada, pluralidade de enfoques), como de suas cinco linhas de pesquisa: A prendizagem e cognição de indivíduos com necessidades especiais de ensino; Currícul o funcional : implementação e avaliação de programas alternativos de ensino especial; Práticas educativas: processos e problemas; Atenção primária e secundária em Educação Especial: prevenção de

\footnotetext{
${ }^{1}$ Fonoaudióloga graduada pela Unesp - Marília, Mestre e Doutoranda em Educação Especial pelo Programa de Pós-graduação em Educação Especial da UFSCar, São Carlos. - e-mail: adrianaaguiar@yahoo.com
} 
deficiências e Produção científica; e formação de recursos humanos em Educação Especial.

O livro retrata a dimensão e importância do evento realizado, bem como a importância de sua continuidade para o crescimento dessa área no país. Está dividido em 15 capítulos, sendo o primeiro relacionado diretamenteàs contribuições do PPGEEs da UFSCar para a Educação Especial brasileira. Também são abordados temas que versam sobre questões relacionadas a pontos mais específicos da Educação Especial, tais como: surdez, surdo-cegueira, população derisco eautismo. Artigos retratando campos teórico-práticos particulares (habilidades sociais); procedimentos (utilização de jogos e atividades lúdicas, atividades motoras adaptadas); demais pessoas envolvidas com a população especial (família e profissionais); formação de professores; inclusão escolar; multiculturalismo e exclusão também são ricamente contemplados.

A incorporação deartigos investigando questões relacionadas à metodologia de pesquisa e a análise dos resultados (no caso a meta-análise), registra ainda a preocupação dos organizadores do congresso e deste livro com o rigor científico tão importante para a geração de estudos frutíferos e grandiosos, como os que vêm sendo produzidos pelo PPGEEs. Com isso, a amplitude dos temas abordados torna-o interessante para diferentes clientelas, tais como: estudantes, profissionais da área, pais, professores do ensino regular e especial etc.

A leitura deste livro e constatação de sua al ta qualidade leva a nós pesquisadores em Educação Especial desejarmos e torcermos pela continuidade desse ideal vislumbrado pelo PPGEEs em parceria com a ABPEE, a partir do reconhecimento de toda a comunidade científica, bem como das importantes agências de fomento à pesquisa que viabilizam essas conquistas. Leva-nos ainda a aguardar ansiosamente pelos próximos eventos e frutos destes para o enriquecimento de uma área tão importante, porém, ainda um pouco carente de maiores investimentos em nosso país. 